\title{
Inhibition of PDGF-BB reduces alkali-induced corneal neovascularization in mice
}

\author{
LEI CHEN $^{1}$, HONGYA WU ${ }^{2}$, CHI REN $^{1}$, GAOQIN LIU $^{1,2}$, WENPENG ZHANG ${ }^{1}$, \\ WEIMING LIU ${ }^{1}$ and PEIRONG LU ${ }^{1,2}$ \\ ${ }^{1}$ Department of Ophthalmology, ${ }^{2}$ Jiangsu Key Laboratory of Clinical Immunology, \\ The First Affiliated Hospital of Soochow University, Suzhou, Jiangsu 215006, P.R. China
}

Received March 27, 2019; Accepted January 8, 2021

DOI: $10.3892 / \mathrm{mmr} .2021 .11877$

\begin{abstract}
The aim of the present study was to investigate the role of platelet-derived growth factor (PDGF)-BB/PDGF receptor $(\mathrm{R})-\beta$ signaling in an experimental murine corneal neovascularization (CrNV) model. Experimental CrNV was induced by alkali injury. The intra-corneal expression of PDGF-BB was examined using immunohistochemistry. The effect of PDGF-BB on CrNV was evaluated using immunofluorescence staining. The expression levels of PDGFR- $\beta$ in human retinal endothelial cells (HRECs) under normal conditions or following cobalt chloride treatment, which induced hypoxic conditions, was assessed using reverse transcription-quantitative PCR. The effect of exogenous treatment of PDGF-BB on the proliferation, migration and tube formation of HRECs under normoxic or hypoxic conditions was evaluated in vitro using Cell Counting Kit-8, wound healing and 3D Matrigel capillary tube formation assays, respectively. The results indicated that the intra-corneal expression levels of the proteins of PDGF-BB and PDGFR- $\beta$ were detectable on days 2 and 7 following alkali injury. The treatment with neutralizing anti-PDGF-BB antibody resulted in significant inhibition of CrNV. The intra-corneal expression levels of vascular endothelial growth factor A, matrix metallopeptidase (MMP)-2 and MMP-9 proteins were downregulated, while the expression levels of thrombospondin (TSP)-1, TSP-2, a disintegrin and metalloproteinase with thrombospondin motifs (ADAMTS)-1 and ADAMTS-2 were upregulated significantly in mice treated with anti-PDGF-BB antibody. The expression levels of PDGFR- $\beta$ were upregulated in HRECs under hypoxic conditions compared with those noted under normoxic conditions. Recombinant human PDGF-BB promoted the proliferation, migration and tube formation of
\end{abstract}

Correspondence to: Professor Peirong Lu or Dr Gaoqin Liu, Department of Ophthalmology, The First Affiliated Hospital of Soochow University, 188 Shizi Street, Suzhou, Jiangsu 215006, P.R. China

E-mail: lupeirong@suda.edu.cn

E-mail: liugaoqin2006@sina.com

Key words: corneal neovascularization, platelet-derived growth factor-BB, endothelial cells, macrophage
HRECs under hypoxic conditions. The data indicated that PDGF-BB/PDGFR- $\beta$ signaling was involved in $\mathrm{CrNV}$ and that it promoted endothelial cell proliferation, migration and tube formation. The pro-angiogenic effects of this pathway may be mediated via the induction of pro-angiogenic cytokine secretion and the suppression of anti-angiogenic cytokine secretion.

\section{Introduction}

Ocular neovascularization is a type of vision-impairment disorder characterized by aberrant or excessive blood vessel formation (1). Choroidal neovascularization (CNV) is a complication noted in the advanced stage of wet-type age-related macular degeneration (AMD), in the retinal neovascularization of diabetic retinopathy subjects, in retinopathy of prematurity and in corneal neovascularization (CrNV) (2). The etiology of the occurrence of CrNV is diverse and includes inflammation, mechanical and chemical injuries (3), as well as hypoxia resulting from improper use of cornea contact lenses (4). During the process of $\mathrm{CrNV}$, disturbed homeostasis of avascular conditions in ocular surfaces may cause persistent and refractory keratitis, and subsequently increase the risk of corneal graft rejection. In certain serious cases, $\mathrm{CrNV}$ can lead to blindness (5). Although clinical treatment targeting the vascular endothelial growth factor (VEGF)-A/VEGF receptor (R)2 signaling pathway has been proven to be an effective approach for wet-type AMD and other ocular neovascular diseases, the side effects and drug resistance, to some extent, partially limit the application of anti-VEGF therapies (6). In addition, it has been demonstrated that multiple other signaling pathways are involved in the development of neovascularization (7). These signaling pathways may exert their function by compensating for VEGF-A pro-angiogenic effects in the process of neovascularization when VEGF-A/VEGFR2 signaling is blocked. Therefore, these compensating effects may reduce the sensitivity of anti-VEGF therapy in certain ocular neovascularization cases (8).

Platelet-derived growth factor (PDGF)-BB is a canonical mitogenic growth factor that mediates specific functions in mural cells, such as pericytes or smooth muscle cells (SMCs) (9). PDGF-BB is mainly produced by the endothelial tip cells of the sprouting new vessels. PDGF-BB can recruit pericytes to the sites of tip cells via binding to 
the receptor of PDGF receptor (R)- $\beta$ (10). The activation of PDGF-BB/PDGFR- $\beta$ signaling is initiated by the auto phosphorylation of PDGFR- $\beta$ and the cascade of intracellular signal transduction is then passed through multiple pathways. These include the PI3K pathway, which is important for chemotaxis and actin re-organization, and the ERK MAP kinase pathway, which is indispensable in the process of cell proliferation $(11,12)$. Furthermore, the AKT and signal transducer and activator of transcription 3 pathways are also involved in PDGF-BB/PDGFR- $\beta$ signal transduction (13). At present, the role of PDGF-BB in promoting and stabilizing the maturation of newly formed vessels has been identified. A previous study that utilized a laser-induced CNV model reported that PDGFR- $\beta$ positive cells were initially located at the site of the Bruch's membrane and were subsequently recruited to the CNV area (14), suggesting that PDGF-BB may be involved in the recruitment of PDGFR- $\beta$ positive cells during CNV. It has also been reported that residual or chemotactic cells other than endothelial cells (ECs) contribute to the elevated expression levels of PDGF-BB $(15,16)$. By cooperating with VEGF-A and/or other cytokines, PDGF-BB recruits ECs/endothelial progenitor cells (EPCs) to lesion sites in order to form tube-like structures (17).

The increased proliferation and migration of vascular ECs is considered an early stage of angiogenesis. A previous study conducted on the overexpression of PDGFR- $\beta$ in spleen-derived EPCs revealed that the proliferation, migration and tube formation of these EPCs were enhanced by stimulation with recombinant PDGF-BB (18). This finding suggested that the interaction between PDGF-BB and PDGFR- $\beta$ contributed to the induction of angiogenesis of EPCs at an early stage. Accumulating evidence has revealed that infiltrated macrophages exert an important role in the early stage of angiogenesis (19). Macrophages can be recruited by hypoxia or inflammatory cytokines, such as hypoxia inducible factor-1 subunit $\alpha$ (HIF-1 $\alpha$ ), C-C motif chemokine receptor (CCL)3, CCL4, tumor necrosis factor $\alpha$, interferon $\gamma$ and interleukin-6 (20,21). The infiltrated macrophages then secrete a series of pro-angiogenic cytokines, such as VEGF-A, PDGF-BB and basic fibroblast growth factor (bFGF) (22). These cytokines exhibit chemotactic effects and recruit ECs from pre-existing vessels (tip cells), which in turn increases the proliferation of ECs (stalk cells) for the formation of new vascular vessels (23). The role of PDGFs that are released by macrophages has predominantly been studied in fibrotic diseases, such as pulmonary, liver, kidney and cardiac fibrosis $(24,25)$. In these pathological conditions, the activated macrophages are the main source of PDGFs, which promote the proliferation of mesenchymal cells (MCs) (26). It is commonly known that PDGFs are also released by ECs and are involved in modulating the process of angiogenesis (27). It is also well-known that Cobalt chloride $\left(\mathrm{CoCl}_{2}\right)$ is a hypoxia-mimic agent that is capable of stabilizing the expression level of HIF-1 $\alpha$ by inhibiting prolyl hydroxylases (PHD) (28). $\mathrm{CoCl}_{2}$ can replace $\mathrm{Fe}^{2+}$ with $\mathrm{Co}^{2+}$ on PHD enzymes and block degradation of HIF- $1 \alpha$ and hence facilitate the establishment of hypoxia conditions in vitro (29). The protocol of inducing hypoxic conditions by $\mathrm{CoCl}_{2}$ is frequently used in related in vitro cellular assays (30-32). Besides, there are also some other hypoxia-mimic agents that can induce and stabilize
HIF-1 $\alpha$ expression, such as desferrioxamine and nickel chloride (33). In the present study, an alkali burn-induced corneal neovascular model was used to investigate the role of PDGF-BB in CrNV in vivo and $\mathrm{CoCl}_{2}$ was employed to induce hypoxic conditions in order to assess the proliferation, migration and tube formation of vascular ECs in vitro.

\section{Materials and methods}

Reagents and antibodies. Human retinal endothelial cells (HRECs) were purchased from Shanghai Yaji Biological Technologies Inc. DMEM and FBS were obtained from HyClone (Cytiva). Cobalt chloride hexahydrate $\left(\mathrm{CoCl}_{2} \cdot 6 \mathrm{H}_{2} \mathrm{O}\right)$ and lipopolysaccharides (LPS) were provided by Sigma-Aldrich (Merck KGaA). AG 1296 (cat. no. S8024) was obtained from Selleck Chemicals. Matrigel Matrix was purchased from BD Biosciences. Cell Counting Kit-8 (CCK-8) was obtained from Dojindo Molecular Technologies, Inc. Rat anti-mouse CD31 antibody (cat. no. MEC13.3) was purchased from BD Pharmingen (BD Biosciences). Alexa Fluor 488-conjugated secondary donkey anti-rat (H+L) antibody (cat. no. A-21208) and Alexa Fluor 594-conjugated secondary goat anti-rabbit $(\mathrm{H}+\mathrm{L})$ antibody (cat. no. R37117) were purchased from Invitrogen (Thermo Fisher Scientific, Inc.). Goat anti-human PDGF-BB antibody (cat. no. ab10845) was purchased from Abcam. Rat anti-mouse F4/80 antibody (cat. no. NB600-404) was from Novus Biologicals, LLC. Rabbit anti-mouse PDGF-BB antibody (cat. no. abs135848) was purchased from Absin Bioscience, Inc. The AxyPrep Multisource Total RNA Miniprep Kit was purchased from Axygen (Corning, Inc.). PrimeScript RT Master Mix and DRR041A SYBR Premix Ex Taq (Perfect Real Time) were purchased from Takara Biotechnology Co., Ltd. Primers were synthesized by Genewiz, Inc.

Induction of CrNV. All animal experiments followed the Guideline for the Care and Use of Laboratory Animals of the Chinese Medical Academy (34) and were approved by the Soochow University Animal Care Committee (Suzhou, China), and were performed in accordance with the ARVO Statement for the Use of Animals in Ophthalmic and Vision Research (35). Specific pathogen-free 8-week-old male C57B/6 $(\mathrm{n}=130$; weighing 20-25 g) were obtained from Shanghai SLAC Laboratory Animal Co., Ltd. The mice were anesthetized with an intraperitoneal injection of $250 \mathrm{mg} / \mathrm{kg}$ of $1.8 \%$ Avertin (Sigma-Aldrich; Merck KGaA). The left eye was treated topically with $0.4 \%$ Benoxil [Santen Pharmaceutical (China) Co., Ltd.] and $2 \times 2 \mathrm{~mm}$ filter paper saturated with $1 \mathrm{~N} \mathrm{NaOH}$ solution was placed on the center of the cornea for $40 \mathrm{sec}$. Subsequently, the corneas were immediately rinsed with balance solution for $15 \mathrm{sec}$. The central epithelia of the corneas were scraped with iris restorer and the layers were immediately treated with ofloxacin eye ointment [Santen Pharmaceutical (China) Co., Ltd.]. The alkali injured mice were divided into 2 groups, namely the vehicle group, which contained mice treated with PBS, and the PDGF-BB antibody group, which included mice treated with an antibody against PDGF-BB. This antibody was dissolved in $2 \%$ hyaluronic acid at a concentration of $50 \mu \mathrm{g} / \mathrm{ml}$. Either PBS or anti-PDGF-BB was applied topically onto the alkali-injured corneas 3 times per day from day 1 to 7 following alkali injury. Each experiment was repeated at least three times. Mice were 
Table I. Sequences of the primers used for reverse transcription-quantitative PCR.

\begin{tabular}{|c|c|c|c|c|}
\hline Gene & Primer sequences $\left(5^{\prime} \rightarrow 3^{\prime}\right)$ & Product size (bp) & Annealing temperature $\left({ }^{\circ} \mathrm{C}\right)$ & PCR cycles \\
\hline$V E G F-A$ & $\begin{array}{l}\text { F: CTGTCTAATGCCCTGGAGCC } \\
\text { R: ACGCGAGTCTGTGTTTTTGC }\end{array}$ & 124 & 60 & 40 \\
\hline$P D G F-B B$ & $\begin{array}{l}\text { F: TTGGACCTGAACATGACCCG } \\
\text { R: ATGGCCGGCTCAGCAATGGTC }\end{array}$ & 101 & 60 & 40 \\
\hline$P D G F R-\beta$ & $\begin{array}{l}\text { F: AGACACGGGAGAATACTTTTGC } \\
\text { R: AGTTCCTCGGCATCATTAGGG }\end{array}$ & 126 & 60 & 40 \\
\hline$T S P-1$ & $\begin{array}{l}\text { F: TGCTATCACAACGGAGTTCAGT } \\
\text { R: GCAGGACACCTTTTTGCAGATG }\end{array}$ & 108 & 60 & 40 \\
\hline$T S P-2$ & $\begin{array}{l}\text { F: GACACGCTGGATCTCACCTAC } \\
\text { R: GAAGCTGTCTATGAGGTCGCA }\end{array}$ & 156 & 60 & 40 \\
\hline ADAMTS-1 & $\begin{array}{l}\text { F: TTCCACGGCAGTGGTCTAAAG } \\
\text { R: CCACCAGGCTAACTGAATTACG }\end{array}$ & 100 & 60 & 40 \\
\hline ADAMTS-2 & $\begin{array}{l}\text { F: GTGCATGTGGTGTATCGCC } \\
\text { R: AGGACCTCGATGTTGTAGTCA }\end{array}$ & 191 & 60 & 40 \\
\hline$M M P-2$ & $\begin{array}{l}\text { F: GATACCCCTTTGACGGTAAGGA } \\
\text { R: CCTTCTCCCAAGGTCCATAGC }\end{array}$ & 112 & 60 & 40 \\
\hline MMP-9 & $\begin{array}{l}\text { F: GGGACGCAGACATCGTCATC } \\
\text { R: TCGTCATCGTCGAAATGGGC }\end{array}$ & 139 & 60 & 40 \\
\hline$\beta$-actin & $\begin{array}{l}\text { F: GCCGTCTTCCCCTCCATCGTG } \\
\text { R: TCTCTTGCTCTGGGCCTCGTC }\end{array}$ & 102 & 60 & 40 \\
\hline
\end{tabular}

All primers used were purchased from Genewiz, Inc. The amplification was performed on iCycler iQ ${ }^{\mathrm{TM}}$ Multi-Color Real Time PCR Detection System (cat. no. 170-8740; Bio-Rad Laboratories, Inc.). F, forward primer; R, reverse primer; VEGF, vascular endothelial growth factor; PDGF, platelet-derived growth factor; TSP, thrombospondin; ADAMTS, a disintegrin and metalloproteinase with thrombospondin motifs; MMP, matrix metalloproteinase.

housed in the animal facility under specific pathogen-free conditions at $23 \pm 3^{\circ} \mathrm{C}$ and $60 \pm 10 \%$ relative humidity and in a $12 / 12 \mathrm{~h}$ day/night cycle with regular lab chow and water available ad libitum. At the indicated time intervals (days 2, 4 and 7 after alkali injury), mice were sacrificed with an intraperitoneal injection of sodium pentobarbitone (Virbac Australia) at a dose of $300 \mathrm{mg} / \mathrm{kg}$ body weight. Mice whose breathing and heartbeat had stopped were considered to be dead. The corneas were removed from the experimental eyes for reverse transcription-quantitative (RT-q)PCR. The corneas were placed immediately into RNAlate (Qiagen $\mathrm{GmbH}$ ) and stored at $-86^{\circ} \mathrm{C}$ until total RNA extraction. For another series of experiments to quantify $\mathrm{CrNV}$ and the double-color immunofluorescence analysis, the mice were sacrificed with an intraperitoneal injection of sodium pentobarbitone at a dose of $300 \mathrm{mg} / \mathrm{kg}$ body weight at the indicated time intervals (days 2,4 or 14 after alkali injury), and the corneas were immediately removed from the alkali-injured eyes.

Quantitation of $C r N V$. Briefly, the clear corneas from the aforementioned alkali-injured eyes were removed rapidly along the limbus with a microscissor. A total of three or four radial relaxing incisions of each cornea were made. The excised corneas from the CrNV assay were rinsed in PBS and fixed in $100 \%$ acetone for $20 \mathrm{~min}$ at room temperature. Following washing and blocking with $2 \%$ BSA (Merck KGaA) in PBS for $1 \mathrm{~h}$ at room temperature, the corneas were stained overnight at $4^{\circ} \mathrm{C}$ with a rat anti-mouse CD31 antibody (1:100). On day 2, CD31 was detected with an Alexa Fluor 488-conjugated secondary donkey anti-rat antibody (1:50) that was incubated for $1 \mathrm{~h}$ at room temperature in the dark. The corneas were transferred to slides, covered with fluorescent mounting medium (Dako; Agilent Technologies, Inc.) and stored at $4^{\circ} \mathrm{C}$ in the dark. The stained whole mounts were analyzed with a fluorescence microscope (MZ16; Leica Microsystems GmbH). Each whole mount image was captured at $\mathrm{x} 25$ magnification. The areas covered with neovascular tubes were determined with ImageJ software (available at http://rsb.info.nih.gov/ij/index.html), version 1.62 (National Institutes of Health). The mean vascularized area of the control whole mounts was defined as $100 \%$; vascularized areas were then related to this value (vessel ratio).

$R T$ - $q P C R$. Total RNA from the corneas and/or HRECs was isolated using the AxyPrep miniprep kit and cDNA was synthesized with the PrimeScript ${ }^{\mathrm{TM}}$ RT Master Mix (Takara Biotechnology Co., Ltd.) according to the manufacturer's protocols. The mRNAs encoding $P D G F-B B, P D G F R-\beta$, $V E G F-A$, matrix metallopeptidase (MMP)-2, MMP-9, thrombospondin (TSP)-1,TSP-2, a disintegrin and metalloproteinase with thrombospondin motifs (ADAMTS)-1 and ADAMTS-2 were amplified using the appropriate primers. The sequences of the PCR primer pairs are listed in Table I. DRR041A SYBR Premix Ex Taq (Perfect Real-Time) was used for qPCR. The 
assay was performed using an $\mathrm{iCycler}_{\mathrm{iQ}} \mathrm{T}^{\mathrm{TM}}$ Multi-Color Real Time PCR detection system (Bio-Rad Laboratories, Inc.). The PCR thermocycling conditions were as follows: Initial denaturation at $95^{\circ} \mathrm{C}$ for $1 \mathrm{~min}$, followed by 40 cycles of denaturation at $95^{\circ} \mathrm{C}$ for $5 \mathrm{sec}$ and annealing at $60^{\circ} \mathrm{C}$ for $30 \mathrm{sec}$. Each sample was assayed in triplicate for both the target and internal control ( $\beta$-actin) genes. Relative quantitative gene expression was calculated using the $2^{-\Delta \Delta \mathrm{Cq}}$ method (36).

Double-color immunofluorescence analysis. For immunofluorescence analysis, the eyes were harvested and rinsed twice with PBS and fixed in $4 \%$ paraformaldehyde for $24 \mathrm{~h}$ at $4^{\circ} \mathrm{C}$ on day 4 following alkali injury. The eyes were subsequently placed in $30 \%$ sucrose for $24 \mathrm{~h}$ and frozen in Tissue-Tek ${ }^{\circledR}$ O.C.T. ${ }^{\mathrm{TM}}$ Compound (Sakura Finetek Japan Co., Ltd.). The samples were cut on a Leica CM3050 S cryotome (8- $\mu \mathrm{m}$ thick). All sections were blocked in 5\% BSA (MP Biomedicals, LLC) for $1 \mathrm{~h}$ at room temperature and subsequently incubated with rat anti-mouse F4/80 (1:100) and rabbit anti-mouse PDGF-BB (1:50) antibodies at $4^{\circ} \mathrm{C}$ overnight. Following rinsing with $\mathrm{PBS}$, the sections were incubated with Alexa Fluor 488-conjugated secondary donkey anti-rat $(\mathrm{H}+\mathrm{L})$ antibody (1:100) and Alexa Fluor 594-conjugated secondary goat anti-rabbit (H+L) antibody (1:100) antibodies for $1 \mathrm{~h}$ at room temperature in the dark. Finally, the sections were washed with PBS, mounted on VECTASHIELD ${ }^{\circledR}$ mounting medium (Vector Laboratories, Inc.) and incubated with DAPI at room temperature for $10 \mathrm{~min}$. Immunofluorescence was visualized with a Nikon Eclipse Ti fluorescence microscope (Nikon Corporation). The images were processed using graphics software (Adobe Photoshop; version 7.0; Adobe Systems, Inc.).

Cell culture. HRECs $\left(3-5 \times 10^{5}\right)$ were cultured in DMEM containing $4.5 \mathrm{mM}$ glucose supplemented with $10 \%(\mathrm{v} / \mathrm{v})$ FBS, $100 \mathrm{U} / \mathrm{ml}$ penicillin and $10 \mu \mathrm{g} / \mathrm{ml}$ streptomycin . The cells were maintained in a humidified incubator with $5 \% \mathrm{CO}_{2}$ atmosphere at $37^{\circ} \mathrm{C}$ and were used for all experiments at a passage number of 2 to 6 .

Proliferation assay. To evaluate the effect of exogenous PDGF-BB on the proliferation of HRECs under normal or hypoxic conditions, a CCK-8 assay was carried out. HRECs were seeded in a 96-well plate $\left(2 \times 10^{3}\right.$ cells per well), and the hypoxic conditions were induced using $200 \mu \mathrm{M}$ of $\mathrm{CoCl}_{2}$ for $12 \mathrm{~h}$. The cells were then treated with recombinant human (rh)-PDGF-BB (Cell Signaling Technology, Inc.) in the presence and/or absence of AG 1296, which is a selective inhibitor of PDGFR- $\beta$. Following incubation for $24 \mathrm{~h}$ at $37^{\circ} \mathrm{C}$, the medium was replaced with fresh DMEM containing CCK-8 (10 $\mu \mathrm{l}$ per well). The cells were subsequently incubated for an additional $2 \mathrm{~h}$. The absorbance was measured at $450 \mathrm{~nm}$ using a microplate reader (Thermo Fisher Scientific, Inc.).

Wound healing assay. The HRECs were cultured in DMEM supplemented with $10 \% \mathrm{FBS}$, pretreated with $\mathrm{CoCl}_{2}(200 \mu \mathrm{M})$ and were seeded into 6 -well plates at a density of $2 \times 10_{5}$ cells per well for $24 \mathrm{~h}$. A control, which was not treated with $\mathrm{CoCl}_{2}$, was included. When HRECs reached $80 \%$ confluence, the cells in each well were scratched perpendicularly using a 200- $\mu 1$ pipette tip at the center of the wells. Briefly, the monolayer of cells was gently and slowly scratched with a new $200-\mu 1$ pipette tip across the center of the well. While scratching across the surface of the well, the long-axial of the tip should always be perpendicular to the bottom of the well. The resulting gap distance is therefore equal to the outer diameter of the end of the tip. A straight line was scratched in one direction. Then, the other two straight lines in parallel with the first line were scratched according to the same protocol. A total of three straight lines were made per well. After scratching, the well was gently washed twice with PBS to remove the detached cells. Fresh serum-free medium (DMEM) was then added into each well. The cells were then treated with PBS (for control and vehicle group) or rh-PDGF-BB protein with or without AG 1296 at $37^{\circ} \mathrm{C}$ for $24 \mathrm{~h}$. The cells were grown at $37^{\circ} \mathrm{C}$ for $48 \mathrm{~h}$, during which images were captured by an Olympus TMS inverted phase contrast microscope (Olympus Corporation) at 0 and $24 \mathrm{~h}$. The width of the gap was evaluated quantitatively using Image J software. The analysis of the distance of migration was performed relative to the starting wound width $(0 \mathrm{~h}$ time-point). The assessment of each experimental group was repeated three times.

Tube formation assay. The in vitro cord formation of HRECs was assessed using Corning Matrigel ${ }^{\circledR}$ Matrix (Coring, Inc.), as described in a previous report with some modifications (37). Briefly, a 96-well plate was incubated on ice and coated with $50 \mu \mathrm{l}$ per well of fully thawed Matrigel for $10 \mathrm{~min}$. The samples were centrifuged at $300 \mathrm{x}$ g for $10 \mathrm{~min}$ at $4^{\circ} \mathrm{C}$ to remove the air bubbles. The samples were subsequently incubated at $37^{\circ} \mathrm{C}$ for $30 \mathrm{~min}$ in order to cause Matrigel solidification. HRECs that were pretreated with $\mathrm{CoCl}_{2}(200 \mu \mathrm{M})$ were cultured in different medium with or without rh-PDGF-BB and/or AG 1296. A control, which was not treated with $\mathrm{CoCl}_{2}$, was included. The cells were seeded on the solidified Matrigel immediately at a density of $1.5 \times 10^{4}$ cells per well. The plates were placed in a humidified atmosphere of $5 \% \mathrm{CO}_{2}$ and $95 \%$ air at $37^{\circ} \mathrm{C}$ for $12 \mathrm{~h}$ to allow the formation of capillary-like structures. Angiogenesis is the formation of capillary tubes and was assessed following $12 \mathrm{~h}$ of cultivation. The tube-like capillary structures were examined under an Olympus TMS inverted phase contrast microscope (Olympus Corporation). The micrographs were captured using an Olympus digital camera.

Statistical analysis. All data are expressed as the mean \pm SEM. Data was analyzed using a Student's t-test (two-tailed) between two groups or by one-way ANOVA with Tukey's multiple comparison within multiple groups using SPSS software version 18.0 (SPSS, Inc.). $\mathrm{P}<0.05$ was considered to indicate a statistically significant difference. Each experiment was independently repeated at least 3 times.

\section{Results}

$C r N V$ is attenuated via inhibition of $P D G F-B B$ in vivo. Initially the role of PDGF-BB in CrNV was explored using a topical treatment of neutralizing anti-PDGF-BB antibody on alkali burned corneas. The area of $\mathrm{CrNV}$ was recorded under a slit-lamp microscope and under a fluorescence microscope following whole mount immunofluorescent staining with an anti-CD31 antibody and an Alexa Fluor 488-conjugated 
A
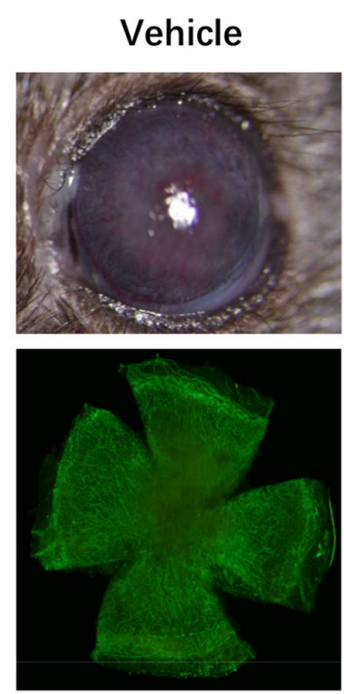

Anti-PDGF-BB
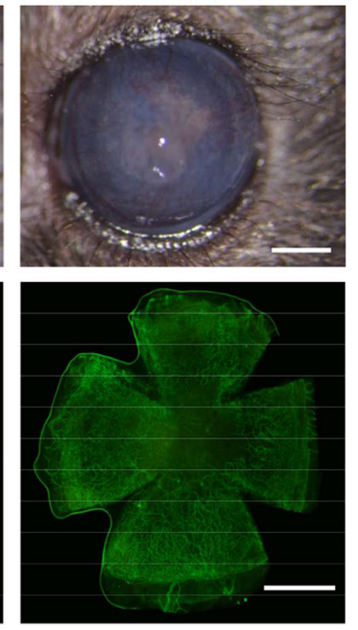

B

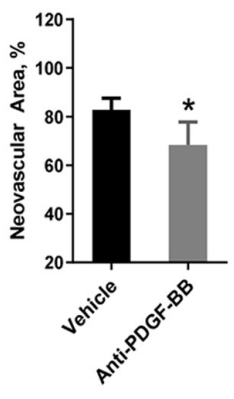

C
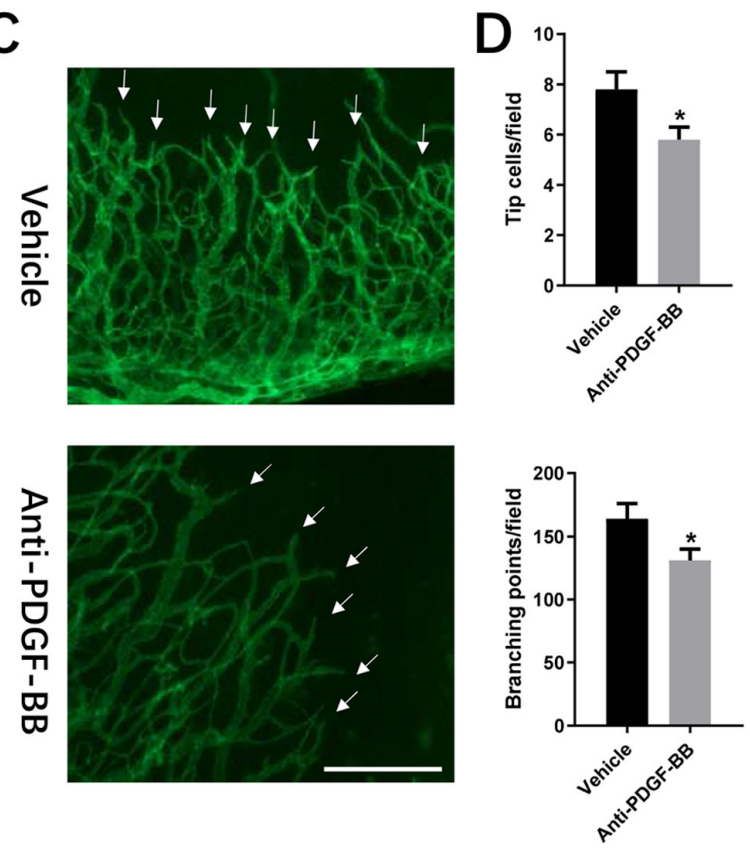

Figure 1. Murine CrNV was suppressed following inhibition of PDGF-BB. CrNV was induced in 8-week old male C57/B6 mice with alkali. Neutralizing PDGF-BB antibody was topically applied from day 1 to day 7 and the gross observation of CrNV was captured by a digital camera under slit-lamp microscope on day 14. Subsequently, corneal flat mount was performed and the vessels were labelled by CD31. (A and B) The percentage of CrNV area was calculated by comparison to the whole cornea area. The CrNV area was reduced following inhibition of PDGF-BB by anti-PDGF-BB (68.37 \pm 3.85 vs. $82.85 \pm 4.66 \%$,

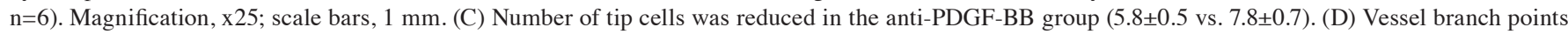

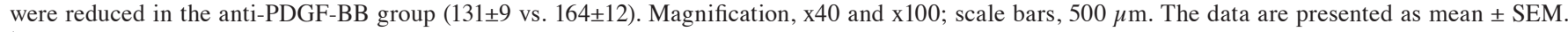
${ }^{*} \mathrm{P}<0.05$ vs. vehicle. PDGF, platelet-derived growth factor; $\mathrm{CrNV}$, corneal neovascularization.

secondary antibody (Fig. 1A). The results indicated that the area of $\mathrm{CrNV}$ was reduced in anti-PDGF-BB-treated groups in comparison with the vehicle-treated group, 2 weeks

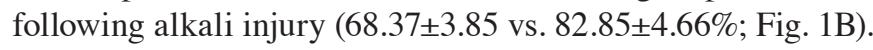
The density of the neovascular in the two groups was also compared (Fig. 1C). The number of branching points and tip cells were also reduced in the anti-PDGF-BB-treated group $(131 \pm 9$ vs. $164 \pm 12 ; 5.8 \pm 0.5$ vs. $7.8 \pm 0.7$; Fig. $1 D)$. The data suggested that the inhibition of PDGF-BB suppressed CrNV and reduced the proliferation of tip cells.

Intra-corneal angiogenesis-related gene expression in the $\mathrm{CrNV}$ model. To investigate the effects of PDGF-BB on CrNV, the expression levels of the angiogenesis-related cytokines were examined at the indicated time-points using RT-qPCR assays. Both PDGF-BB and PDGFR- $\beta$ were expressed at the early stage of CrNV (days 2, 4 and 7 following alkali injury). At these indicated time-points, the results showed that the expression levels of $P D G F-B B$ and PDGFR- $\beta$ (both in vehicle and anti-PDGF-BB groups) were highest on day 4 after alkali injury compared with the expression levels of $P D G F-B B$ and $P D G F R-\beta$ on days 2 and 7 , and the expression levels of $P D G F-B B$ and $P D G F R-\beta$ (both in vehicle and anti-PDGF-BB groups) were downregulated on day 7 compared with expression levels of $P D G F-B B$ and $P D G F R-\beta$ on day 4 . The dynamic intracorneal expression of PDGF-BB and PDGFR- $\beta$ suggested the possible involvement of PDGF-BB/PDGFR- $\beta$ interactions in alkali-induced $\mathrm{CrNV}$. The intra-corneal expression levels of $V E G F-A, M M P-2$ and $M M P-9$ were reduced, while the expression levels of TSP-1, TSP-2, ADAMTS-1 and ADAMTS-2 were increased in the anti-PDGF-BB-treated group compared with those of the vehicle-treated group (Fig. 2). These data suggested that the inhibition of PDGF-BB decreased the expression levels of the pro-angiogenic factors VEGF-A, MMP-2 and MMP-9 and increased the expression levels of the anti-angiogenic factors TSP-1, TSP-2, ADAMTS-1 and ADAMTS-2.

Intra-corneal infiltrated macrophages produces PDGF-BB. Subsequently, the types of cells responsible for the secretion of PDGF-BB were examined. It is commonly known that infiltrated inflammatory cells, such as macrophages, play an important role in the early stages of angiogenesis by secreting a series of angiogenic cytokines $(38,39)$. Therefore, the number of intracorneal macrophages were detected and it was determined whether PDGF-BB was expressed by macrophages using immunohistochemical assays. The results indicated that PDGF-BB was detectable in F4/80 positive cells on day 4 following alkali injury (Fig. 3). This finding suggested that intra-corneal macrophages may express PDGF-BB and that they could be one of the sources of PDGF-BB secretion.

Expression of PDGFR- $\beta$ is upregulated in HRECs under inflammatory or hypoxic conditions. The expression of PDGFR- $\beta$ in HRECs under different conditions was also examined. RT-qPCR indicated that PDGFR- $\beta$ was expressed in HRECs at a low level and that the expression levels of PDGFR- $\beta$ in HRECs increased in a concentration-dependent manner when the cells were treated with LPS or $\mathrm{CoCl}_{2}$ to induce inflammatory or hypoxic conditions (Fig. 4A).

PDGF-BB promotes proliferation, migration and tube formation of HRECs. Subsequently, it was investigated whether 

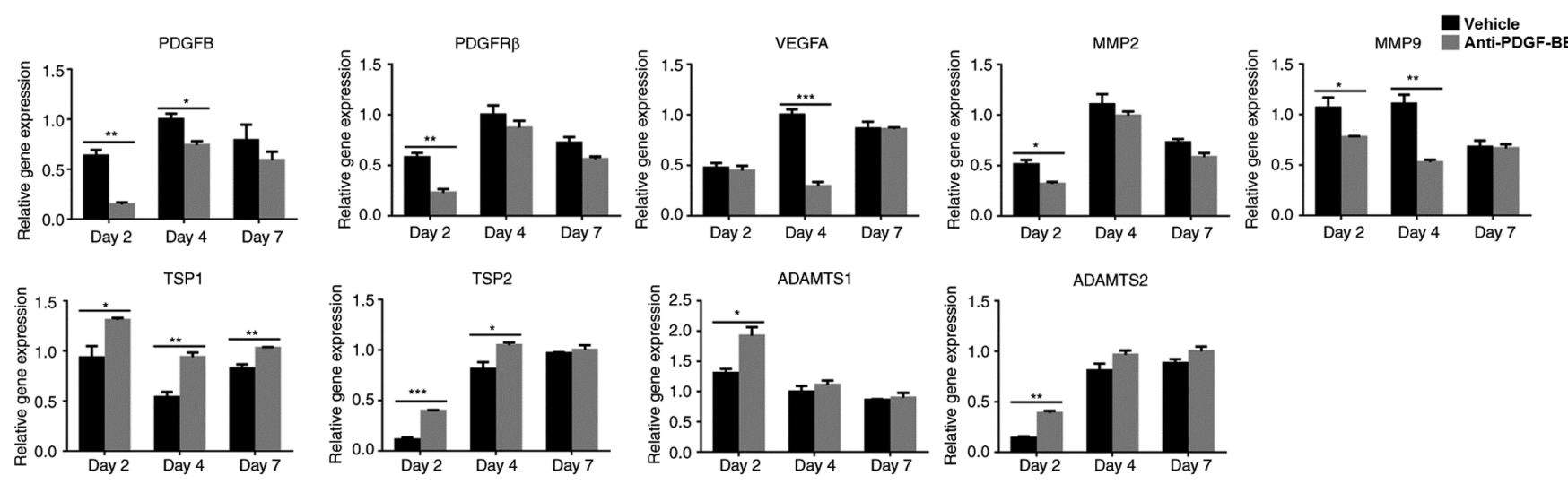

Figure 2. Expression levels of pro-angiogenic genes were downregulated and the expression levels of anti-angiogenic genes were upregulated following inhibition of PDGF-BB in the CrNV model. Total mRNA was extracted from corneas on days 2,4 and 7 following treatment with alkali. The expression levels of the angiogenic genes were detected by reverse transcription-quantitative PCR. The levels of $P D G F-B, P D G F R-\beta, V E G F-A, M M P-2$ and $M M P-9$ were downregulated in the anti-PDGF-BB group, whereas the expression levels of TSP-1, TSP-2, ADAMTS-1 and ADAMTS-2 were upregulated. The data are presented as mean \pm SEM. ${ }^{*} \mathrm{P}<0.05,{ }^{* * *} \mathrm{P}<0.01,{ }^{* * * *} \mathrm{P}<0.001$. PDGF, platelet-derived growth factor; PDGFR- $\beta$, platelet-derived growth factor receptor; CrNV, corneal neovascularization; VEGF, vascular endothelial growth factor; MMP, matrix metalloproteinase; TSP, thrombospondin; ADAMTS, a disintegrin and metalloproteinase with thrombospondin motifs.
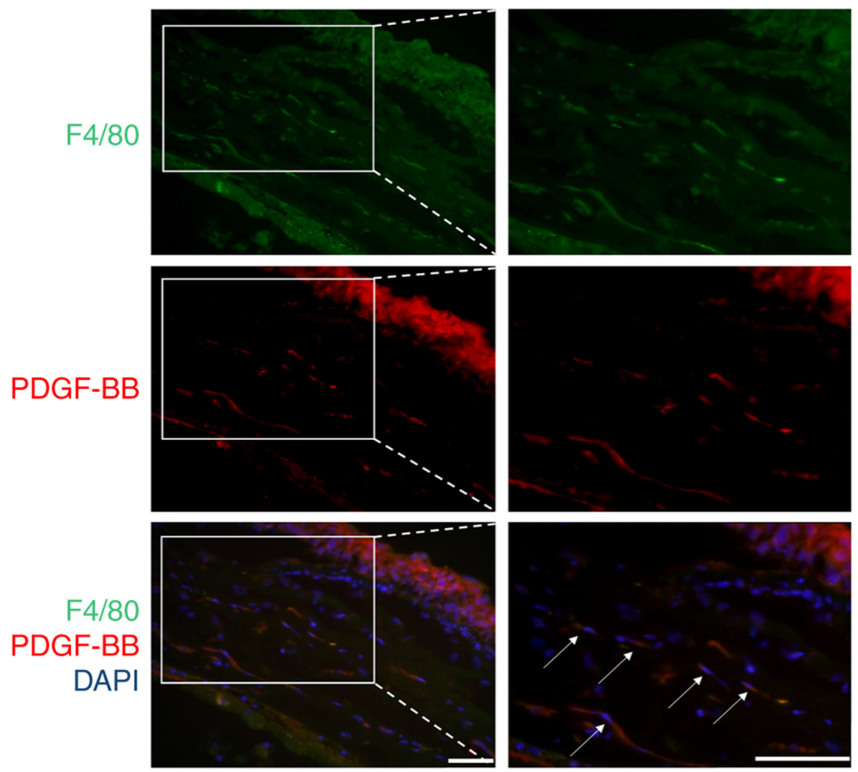

Figure 3. PDGF-BB was partially derived from infiltrated macrophages in the CrNV model. The eyes of the animals from the induced CrNV model were enucleated on day 4, and the expression levels of F4/80 and PDGF-BB were detected using immunohistochemistry. The sections were fixed in $4 \%$ paraformaldehyde and incubated with primary anti-mouse F4/80 and anti-mouse PDGF-BB antibodies for staining. Alexa Fluor 488 (green) and Alexa Fluor 594 (red) secondary antibodies were used to bind to the anti-F4/80 and anti-PDGF-BB antibodies, respectively, whereas the nuclei were counterstained with DAPI. On day 4, F4/80 positive cells were detected in the stroma of cornea, and part of F4/80 positive cells were co-localized with PDGF-BB (white arrows). Magnification, x10 left panel, x200 right panel. Representative images from 3 independent experiments are shown. Scale bar, $50 \mu \mathrm{m}$. Arrows indicate the double-positive cells. PDGF, platelet-derived growth factor; CrNV, corneal neovascularization.

PDGF-BB/PDGFR- $\beta$ signaling affects the proliferation of vascular ECs. The results indicated that the proliferation of HRECs was increased in the rh-PDGF-BB treated group, in which cells were pretreated with $\mathrm{CoCl}_{2}$ compared with the PBS-treated control and the rh-PDGF-BB-treated groups that were not exposed to $\mathrm{CoCl}_{2}(1.675 \pm 0.75$ vs. $1.103 \pm 0.11)$.
This effect was inhibited when the cells were treated with the PDGFR- $\beta$ inhibitor, AG 1296 (1.232 \pm 0.09 ; Fig. 4B).

To assess the effects of rh-PDGF-BB on the migration of HRECs, the distance of migration was compared between vehicle and experimental groups using a wound healing assay. The mobility of HRECs that were pretreated with $\mathrm{CoCl}_{2}$ was increased by treatment with rh-PDGF-BB $(232 \pm 10.32$ vs. $185 \pm 6.43 \mu \mathrm{m})$ compared with that of PBS-treated cells following $24 \mathrm{~h}$ incubation from the scratch (Fig. 5A). This positive effect was inhibited by administration of AG 1296 (210 $\pm 10.60 \mu \mathrm{m}$; Fig. 5B).

To further evaluate the effects of the PDGF-BB/PDGFR- $\beta$ signaling pathway on the biological function of HRECs in the formation of vascular cells, a tube formation assay was performed using rh-PDGF-BB and AG 1296. The results indicated that rh-PDGF-BB $(20 \mathrm{ng} / \mathrm{ml})$ increased tube formation of HRECs, while this effect was abrogated when the cells were further treated with AG 1296 (Fig. 6A). It was evident by the formation of additional branch points (vehicle group was $117.3 \pm 5.94$, rh-PDGF-BB group was $153.0 \pm 4.30$ and rh-PDGF-BB+AG1296 group was 127.5 \pm 7.01 ; Fig. 6B), and total tube length (vehicle group was $14,064 \pm 404.3 \mu \mathrm{m}$, rh-PDGF-BB group was $18,604 \pm 738.7 \mu \mathrm{m}$ and rh-PDGF-BB+AG1296 group was; $15,957 \pm 488.4 \mu \mathrm{m}$; Fig. $6 \mathrm{C}$ ). The results suggested that PDGF-BB could promote proliferation, migration and tube formation of HRECs in vitro under hypoxic conditions.

\section{Discussion}

Corneal transparency is required for optimal vision. The invasion of new vessels from the corneal limbus to the normal avascular corneal stroma, causes the impairment of the avascular state of the cornea, which can result in visual damage and even lead to blindness (40). Angiogenesis is a complex process involving interactions of multiple ligand/receptor signaling pathways and cell types, as well as the modulation of various cytokines (41). The process consists of two stages of vessel bud formation resulting from migration and proliferation of vascular ECs, and the maturation of vascular tubes (42). 

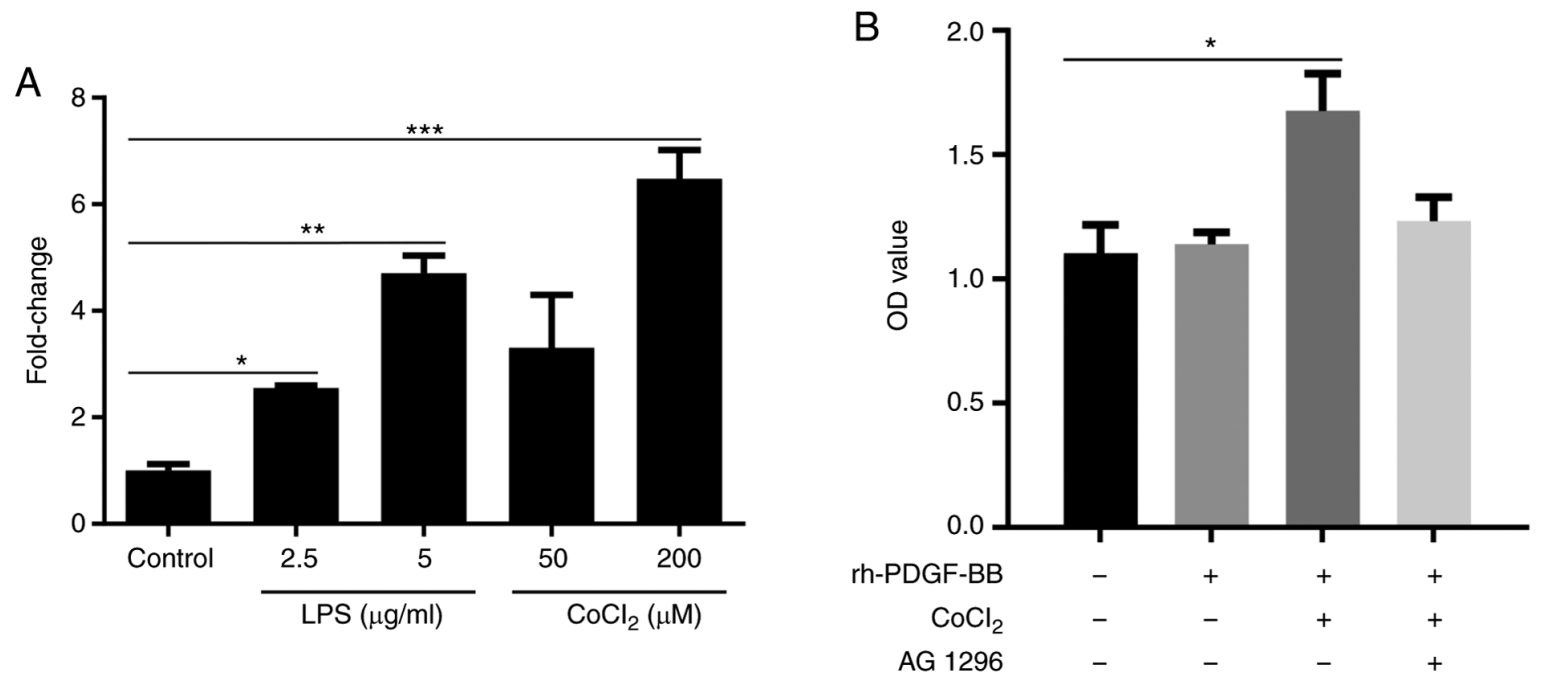

Figure 4. Expression of PDGFR- $\beta$ in HRECs and the effect of rh-PDGF-BB on the proliferation of HRECs. (A) PDGFR- $\beta$ was expressed at low levels in HRECs and was upregulated significantly following induction with LPS (2.54-fold increase at $2.5 \mu \mathrm{g} / \mathrm{ml}, 4.70$-fold increase at $5 \mu \mathrm{g} / \mathrm{ml})$ or CoCl ${ }_{2}(6.47$-fold increase at $200 \mu \mathrm{M})$. (B) Normoxic and hypoxic HRECs (treated with $\left.20 \mathrm{mM} \mathrm{CoCl}_{2}\right)$ incubated with rh-PDGF-BB $(20 \mathrm{ng} / \mathrm{ml})$ with or without AG $1296(1 \mu \mathrm{M})$. rh-PDGF-BB promoted the proliferation of HRECs when the expression of PDGFR- $\beta$ was upregulated under hypoxia (1.675 \pm 0.75 vs. $1.103 \pm 0.11)$, and the increased proliferation was inhibited by AG $1296(1.232 \pm 0.09)$. The data are presented as mean \pm SEM. ${ }^{*} \mathrm{P}<0.05,{ }^{* *} \mathrm{P}<0.01,{ }^{* * * *} \mathrm{P}<0.001$. PDGFR, platelet-derived growth factor receptor; HRECs, human retinal endothelial cells; LPS, lipopolysaccharide; $\mathrm{CoCl}_{2}, \mathrm{Cobalt}$ chloride; rh, recombinant human.

A
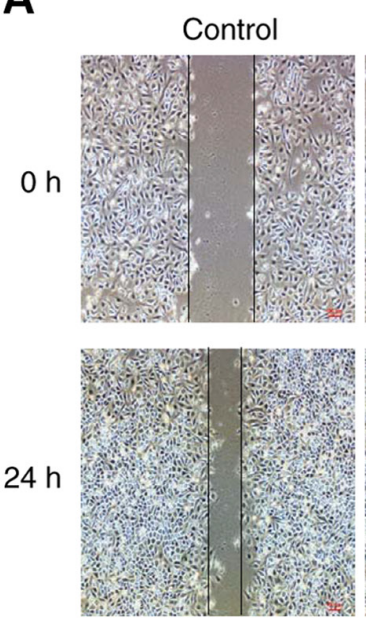

Vehicle
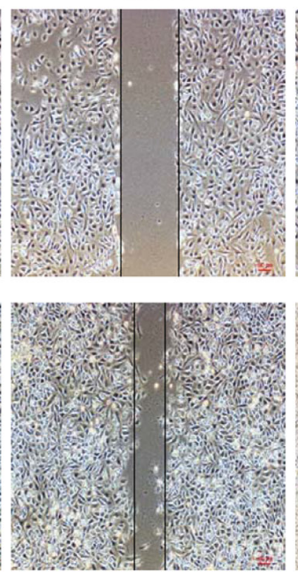

rh-PDGF-BB
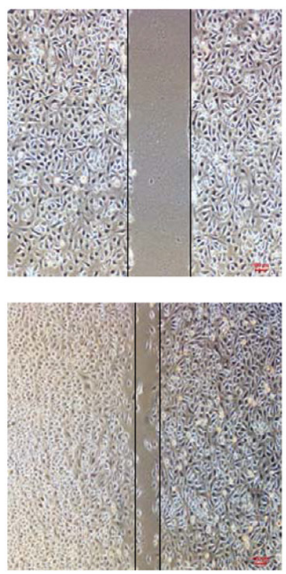

rh-PDGF-BB+ AG 1296
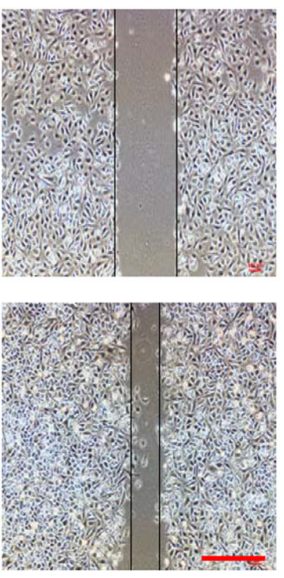

B

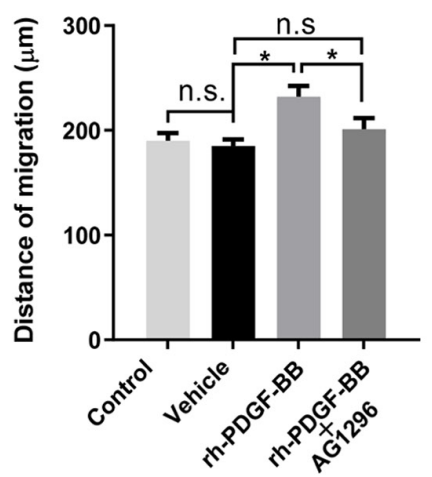

Figure 5. Effects of rh-PDGF-BB on the migration of HRECs. (A) HRECs were pretreated with $200 \mathrm{mM} \mathrm{CoCl}_{2}$ and were seeded into a 6-well plate at a density of $2 \times 10^{5}$ cells per well. A scratch was made at $80 \%$ confluence. The vehicle group was incubated with fresh medium containing equivalent amounts of solvent (acetic acid), whereas $20 \mathrm{ng} / \mathrm{ml}$ rh-PDGF-BB with or without AG $1296(1 \mu \mathrm{M})$ were added to the experimental groups and the migrated distance was recorded at 0 and $24 \mathrm{~h}$. Magnification, x100; scale bar, $500 \mu \mathrm{m}$. (B) Corresponding histogram showing that the distance of the rh-PDGF-BB group was increased compared with that of the vehicle group at $24 \mathrm{~h}(233 \pm 10.32 \mathrm{vs} .185 \pm 6.43 \mu \mathrm{m})$ and no difference was found between the vehicle and the rh-PDGF-BB plus AG 1296 groups $(210 \pm 10.60 \mu \mathrm{m})$. Representative images from 3 independent experiments are shown and the data are presented as mean \pm SEM, ${ }^{*} \mathrm{P}<0.05$. n.s., no significance; PDGF, platelet-derived growth factor; rh, recombinant human; HRECs, human retinal endothelial cells.

This process includes an event of recruiting mural cells from pericytes and/or SMC (43). PDGF-BB is a well-characterized trophic factor that is crucial for biological functions, such as survival and proliferation of various cells including pericytes and SMC (10). Furthermore, it has been shown that PDGF-BB is produced by vascular ECs and contributes to maintaining the maturity of newly formed vessels (27). Studies have demonstrated that during fibrosis, MCs, such as pericytes and SMCs, are recruited and further differentiated into fibroblasts by PDGF-BB, these cells promote the formation of local fibrosis and lesion scars $(26,44)$. Furthermore, the expression of PDGFR- $\beta$, the receptor of PDGF-BB, has been reported in EPCs, which are the precursor cells for vascular ECs (45). A previous study has also shown that the expression of PDGFR- $\beta$ in EPCs promotes the migration and proliferation of vascular ECs and angiogenesis by interacting with PDGF-BB (46). Exogenous PDGF-BB was shown to promote early migration of cells following wound healing in a rat rotator cuff repair model (47). Previous studies have indicated that PDGF-BB/PDGFR- $\beta$ signaling is very important in maintaining the maturity of vessels via the recruitment of pericytes in the advanced stages of angiogenesis $(10,44,48)$. However, the PDGF-BB/PDGFR- $\beta$ signaling has not yet been well characterized during $\mathrm{CrNV}$. In the present study, 
A

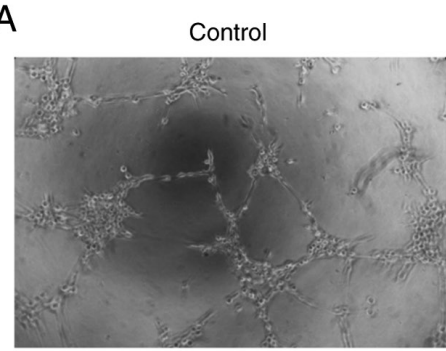

rh-PDGF-BB

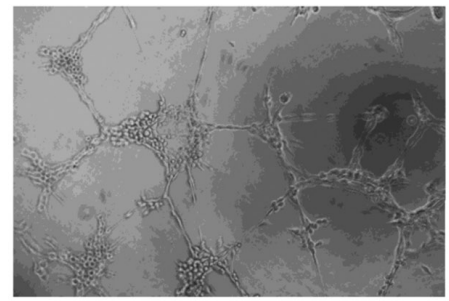

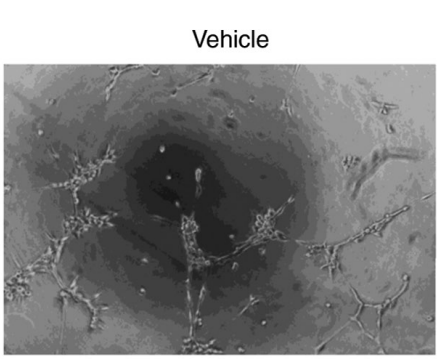

rh-PDGF-BB+ AG1296

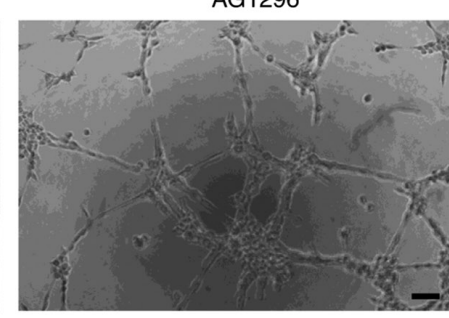

B
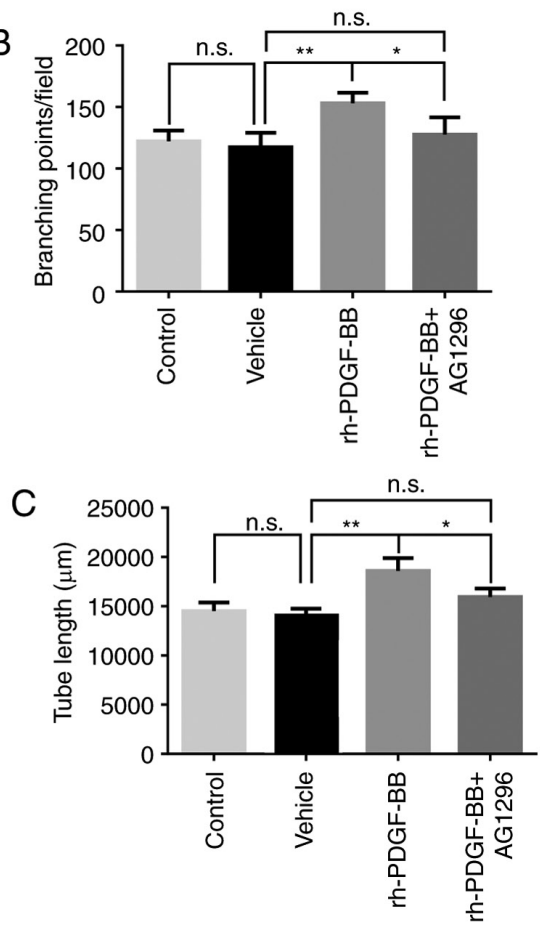

Figure 6. Effects of rh-PDGF-BB on tube formation of HRECs. (A) HRECs were pretreated with $200 \mathrm{mM} \mathrm{CoCl}_{2}$ and were seeded on a Matrigel coated 96 -well plate at a density of $1 \times 10^{4}$ cells per well. Digital microphotographs were obtained from 5 randomly selected high-power fields following $6 \mathrm{~h}$ of incubation in different cultures (vehicle, $20 \mathrm{ng} / \mathrm{ml}$, rh-PDGF-BB with or without $1 \mu \mathrm{M}$ AG 1296). Magnification, x100; scale bar, 200 $\mu \mathrm{m}$. (B) Branch points and (C) tube lengths in the rh-PDGF-BB group were increased compared with those of the vehicle group $(153.0 \pm 4.30 \mathrm{vs}$. 117.3 $\pm 5.94,18,604 \pm 738.7 \mathrm{vs}$. $14,064 \pm 404.3 \mu \mathrm{m})$, and this increase was inhibited with AG 1296 treatment $(127.5 \pm 7.01,15,957 \pm 488.4 \mu \mathrm{m})$. The data are presented as mean $\pm \mathrm{SEM},{ }^{*} \mathrm{P}<0.05,{ }^{* *} \mathrm{P}<0.01 . \mathrm{n} . \mathrm{s} .,{ }^{2}$ no significance; PDGF, platelet-derived growth factor; rh, recombinant human; $\mathrm{HRECs}$, human retinal endothelial cells; $\mathrm{CoCl}_{2}$, Cobalt chloride.

the intra-corneal expression of PDGFR- $\beta$ and the role of PDGF-BB/PDGFR- $\beta$ signaling in $\mathrm{CrNV}$ following alkali injury were investigated.

The results indicated that PDGFR- $\beta$ was dynamically expressed in corneas in a murine CrNV model on days 2 and 7 following alkali injury, suggesting the possible involvement of PDGF-BB/PDGFR- $\beta$ signaling in the process of $\mathrm{CrNV}$. Further analysis revealed that $\mathrm{CrNV}$ was suppressed when the corneas were topically treated with neutralizing anti-PDGF-BB antibody, suggesting that blockage of PDGF-BB could inhibit neovascularization of the cornea. The intra-corneal dynamic expression of angiogenesis-associated cytokines, such as the pro-angiogenic factors $V E G F-A, M M P-2$ and $M M P-9$, and the anti- angiogenic factors TSP-1, TSP-2, ADAMTS-1 and $A D A M T S-2$, was assessed between the vehicle and the neutralizing anti-PDGF-BB antibody-treated groups. The data indicated that the mRNA expression levels of $V E G F-A$, $M M P-2$ and $M M P-9$ were increased and that the expression levels of TSP-1, TSP-2, ADAMTS-1 and ADAMTS-2 were reduced when the biological function of PDGF-BB was blocked by the neutralizing anti-PDGF-BB antibody, suggesting that PDGF-BB was involved in the regulation of the expression of these cytokines. The results were in agreement with a previous study by Park et al (49), which showed that the pro-angiogenic effect of PDGF-BB was impaired by inhibition of PDGF-BB/PDGFR- $\beta$ signaling, resulting in suppressed expression of MMP-2 and MMP-9. The data from the present study and previous reports supports the hypothesis that PDGF-BB/PDGFR- $\beta$ may have an important role in the early stages of $\mathrm{CrNV}$.
The expression levels of PDGFR- $\beta$ in HRECs were further investigated under different conditions, and the effects of rh-PDGF-BB on proliferation, migration and tube formation of these cells were explored in vitro. Although PDGF-BB/PDGFR- $\beta$ signaling was reported to exert a significant role in embryonic and pathological vascular formation (50), the expression levels of PDGFR- $\beta$ in ECs were not determined. During the course of embryonic development, PDGFR- $\beta$ expression is ubiquitous and is noted in several cell types, including ECs and pericytes. However, PDGFR- $\beta$ expression levels are downregulated postnatally (51). The upregulation of the expression levels of PDGFR- $\beta$ on EPCs is also reported under some pathological conditions, such as inflammation, wound healing and tumorigenesis. Upon activation of PDGF-BB/PDGFR- $\beta$ signaling, the infiltration of EPCs is facilitated and leads to differentiation from progenitor cells into ECs. Moreover, the proliferation and mobility of ECs are also enhanced (52). In addition to the effect of PDGF-BB/PDGFR- $\beta$ signaling on EPCs, this pathway exerts proliferative and chemotactic effects on lymphatic ECs (53). In the present study, it was demonstrated that the expression levels of PDGFR- $\beta$ on HRECs were significantly increased in a dose dependent manner when HRECs were stimulated with LPS or $\mathrm{CoCl}_{2}$, indicating that the expression levels of PDGFR- $\beta$ could be regulated under specific conditions, such as inflammation or hypoxia, which are common causes for postnatal pathological angiogenesis (43). Furthermore, the proliferation, migration and tube formation of HRECs were also increased when the cells were pretreated with $\mathrm{CoCl}_{2}$ and further treated with rh-PDGF-BB. In contrast to rh-PDGF-BB, the aforementioned 
biological functions of HRECs were suppressed when the cells were pretreated with $\mathrm{CoCl}_{2}$ and further treated with AG 1296, an inhibitor used for the PDGF-BB receptor. These in vitro results suggested that the interactions between PDGF-BB and PDGFR- $\beta$ can promote angiogenesis in $\mathrm{CoCl}_{2}$-stimulated HRECs.

A previous study demonstrated that ECs can be activated by inflammatory cells, such as macrophages, via the secretion of pro-angiogenic factors (54). PDGF-BB is a pro-angiogenic factor with the ability to activate ECs, and is also possibly secreted by inflammatory cells in alkali-injured corneas (55). In the present study, the intra-corneal expression levels of PDGF-BB were examined. Considering that macrophages are an important source for the secretion of pro-angiogenic factors, such as VEGF-A, bFGF and MMP-9 (39), the expression levels of PDGF-BB in F4/80 positive macrophages were investigated using immunohistochemical methods. The results indicated that PDGF-BB was expressed in F4/80 positive macrophages in alkali-injured corneas, suggesting that F4/80 positive macrophages can be considered an important source for PDGF-BB. The secretion of this growth factor activates ECs by binding with its receptor and therefore serving a significant role in CrNV (56). To the best of the authors' knowledge, it is still unclear whether PDGF-BB is derived from macrophages. In the present study, the data suggested that PDGF-BB could be secreted from infiltrated macrophages in the CrNV model. This is a novel finding that may be useful to further understand the underlying mechanism of macrophage regulation during CrNV.

In the present study, the results demonstrated that $\mathrm{CrNV}$ was suppressed in vivo via the inhibition of PDGF-BB at the early stages of angiogenesis. The expression levels of the angiogenic genes, namely $V E G F-A, M M P-2$ and $M M P-9$ were enhanced, while the expression levels of TSP-1, TSP-2, ADAMTS- 1 and ADAMTS-2 were reduced following treatment with the rh-PDGF-BB protein. In addition, exogenous PDGF-BB promoted proliferation, migration and tube formation of hypoxic-HRECs in vitro and provided evidence that PDGF-BB may exert a critical role in experimental CrNV. However, there are some limitations of the present study. First, the mechanism of increased intra-corneal expression of PDGF-BB/PDGFR- $\beta$ after alkali injury is still unclear and needs to be further explored. Second, it would be more useful to additionally apply PDGFR- $\beta$ knockout mice to examine the effects of PDGF-BB/PDGFR- $\beta$ in alkali-burned CrNV by comparing groups among vehicle (wild-type)-treated mice, anti-PDGF-BB-treated mice and PDGFR- $\beta$ knockout mice. Third, it would be more suitable to choose a vascular EC line that originated from corneal neovascular in this study when performing the relevant in vitro experiments. However, considering that there are still no vascular EC lines originating from CrNV worldwide, HRECs had to be used to perform in vitro experiments.

In summary, the present study demonstrated that the PDGF-BB/PDGFR- $\beta$ signaling pathway exerts multiple activities, including mitogenesis, angiogenesis and macrophage activation (57). The data indicated that endogenous PDGF-BB is partially derived from infiltrated macrophages and that the PDGF-BB/PDGFR- $\beta$ pathway played an important role in the early stages of angiogenesis in the CrNV model. The findings of the present study may aid the understanding of the role of PDGF-BB in angiogenesis and could provide novel options to target PDGF-BB in the treatment of angiogenesis.

\section{Acknowledgements}

Not applicable.

\section{Funding}

The present study was supported by the National Natural Science Foundation in China (grant nos. 81970830, 81671641, 81200727 and 31600736), Suzhou Municipal Natural Science Foundation (grant no. SYS201745), Jiangsu Provincial Medical Youth Talent (grant no. QNRC2016718), Jiangsu Provincial Medical Innovation Team (grant no. CXTDA2017039) and the Soochow Scholar Project of Soochow University (grant no. R5122001).

\section{Availability of data and materials}

All data generated or analyzed during this study are included in this published article.

\section{Authors' contributions}

LC, GL confirm the authenticity of all the raw data. LC, GL and HW designed the study, led the experiments, prepared figures and wrote the manuscript. CR, LC, WZ and WL analyzed the data and prepared the figures. PL and GL conceived, designed and coordinated the study, and drafted the manuscript. All authors read and approved the final manuscript.

\section{Ethics approval and consent to participate}

All animal experiments followed the Guideline for the Care and Use of Laboratory Animals of the Chinese Medical Academy and were approved by the Soochow University Animal Care Committee (approval number 202012A121, Suzhou, China), and were performed in accordance with the ARVO Statement for the Use of Animals in Ophthalmic and Vision Research.

\section{Patient consent for publication}

Not applicable.

\section{Competing interests}

The authors declare that they have no competing interests.

\section{References}

1. Campochiaro PA: Ocular neovascularization. J Mol Med (Berl) 91: 311-321, 2013

2. Cheung LK and Eaton A: Age-related macular degeneration. Pharmacotherapy 33: 838-855, 2013.

3. Clements JL and Dana R: Inflammatory corneal neovascularization: Etiopathogenesis. Semin Ophthalmol 26: 235-245, 2011

4. Yeung KK, Yang HJ, Nguyen AL and Weissman BA: Critical contact lens oxygen transmissibility and tearlens oxygen tension to preclude corneal neovascularization. Eye Contact Lens 44 (Suppl 1): S291-S295, 2018. 
5. Voiculescu OB, Voinea LM and Alexandrescu C: Corneal neovascularization and biological therapy. J Med Life 8: 444-448, 2015

6. Rahbari NN, Kedrin D, Incio J, Liu H, Ho WW, Nia HT,Edrich CM, Jung K, Daubriac J, Chen I, et al: Anti-VEGF therapy induces ECM remodeling and mechanical barriers to therapy in colorectal cancer liver metastases. Sci Transl Med 8: 360ra135, 2016.

7. Cabral T, Mello LGM, Lima LH, Polido J, Regatieri CV, Belfort R Jr and Mahajan VB: Retinal and choroidal angiogenesis: A review of new targets. Int J Retina Vitreous 3: 31, 2017.

8. Zhao Y and Adjei AA: Targeting angiogenesis in cancer therapy: Moving beyond vascular endothelial growth factor Oncologist 20: 660-673, 2015.

9. Hellberg C, Ostman A and Heldin CH: PDGF and vessel maturation. Recent Results Cancer Res 180: 103-114, 2010.

10. Lindblom P, Gerhardt H, Liebner S, Abramsson A, Enge M, Hellstrom M, Backstrom G, Fredriksson S, Landegren U, Nystrom HC, et al: Endothelial PDGF-B retention is required for proper investment of pericytes in the microvessel wall. Genes Dev 17: 1835-1840, 2003

11. Dell S, Peters S, Müther P, Kociok N and Joussen AM: The role of PDGF receptor inhibitors and PI3-kinase signaling in the pathogenesis of corneal neovascularization. Invest Ophthalmol Vis Sci 47: 1928-1937, 2006.

12. Ricci C and Ferri N: Naturally occurring PDGF receptor inhibitors with potential anti-atherosclerotic properties. Vascul Pharmacol 70: 1-7, 2015.

13. Park DY, Lee J, Kim J, Kim K, Hong S, Han S, Kubota Y, Augustin HG, Ding L, Kim JW, et al: Plastic roles of pericytes in the blood-retinal barrier. Nat Commun 8: 15296, 2017.

14. Strittmatter K, Pomeroy $\mathrm{H}$ and Marneros AG: Targeting platelet-derived growth factor receptor $\beta(+)$ scaffold formation inhibits choroidal neovascularization. Am J Pathol 186: 1890-1899, 2016

15. Ho CL, Hsu LF, Phyliky RL and Li CY: Autocrine expression of platelet-derived growth factor B in B cell chronic lymphocytic leukemia. Acta Haematol 114: 133-140, 2005

16. Koehler NK, Roebbert M, Dehghani K, Ballmaier M, Claus P, von Hoersten S, Shing M, Odin P, Strehlau J and Heidenreich F: Up-regulation of platelet-derived growth factor by peripheral-blood leukocytes during experimental allergic encephalomyelitis. J Neurosci Res 86: 392-402, 2008.

17. Minardi S, Pandolfi L, Taraballi F, Wang X, De Rosa E, Mills ZD, Liu X, Ferrari M and Tasciotti E: Enhancing vascularization through the controlled release of platelet-derived growth factor-BB. ACS Appl Mater Interfaces 9: 14566-14575, 2017.

18. Wang H, Yin Y, Li W, Zhao X, Yu Y, Zhu J, Qin Z, Wang Q, Wang $\mathrm{K}, \mathrm{Lu} \mathrm{W}$, et al: Over-expression of PDGFR- $\beta$ promotes PDGF-induced proliferation, migration, and angiogenesis of EPCs through PI3K/Akt signaling pathway. PLoS One 7: e30503, 2012.

19. Lu P, Li L, Liu G, van Rooijen N, Mukaida N and Zhang X: Opposite roles of CCR2 and CX3CR1 macrophages in alkali-induced corneal neovascularization. Cornea 28: 562-569, 2009.

20. Rhee I: Diverse macrophages polarization in tumor microenvironment. Arch Pharm Res 39: 1588-1596, 2016.

21. Qian BZ and Pollard JW: Macrophage diversity enhances tumor progression and metastasis. Cell 141: 39-51, 2010.

22. Mayer A, Lee S, Jung F, Grütz G, Lendlein A and Hiebl B: $\mathrm{CD}_{14}{ }^{+} \mathrm{CD} 163^{+} \mathrm{IL}-10^{+}$monocytes/macrophages: Pro-angiogenic and non pro-inflammatory isolation, enrichment and long-term secretion profile. Clin Hemorheol Microcirc 46: 217-223, 2010.

23. Marçola M and Rodrigues CE: Endothelial progenitor cells in tumor angiogenesis: Another brick in the wall. Stem Cells Int 2015: 832649, 2015

24. Noskovičová N, Petřek M, Eickelberg O and Heinzelmann K; From Lung Development and Disease to Clinical Studies: Platelet-derived growth factor signaling in the lung. From lung development and disease to clinical studies. Am J Respir Cell Mol Biol 52: 263-284, 2015.

25. Ostendorf T, Boor P, van Roeyen CR and Floege J: Platelet-derived growth factors (PDGFs) in glomerular and tubulointerstitial fibrosis. Kidney Int Suppl (2011) 4: 65-69, 2014.

26. Jaguin M, Fardel $O$ and Lecureur V: AhR-dependent secretion of PDGF-BB by human classically activated macrophages exposed to DEP extracts stimulates lung fibroblast proliferation. Toxicol Appl Pharmacol 285: 170-178, 2015.

27. Kryza T, Achard C, Parent C, Marchand-Adam S, Guillon-Munos A, Iochmann S, Korkmaz B, Respaud R, Courty Y and Heuzé-Vourc'h N: Angiogenesis stimulated by human kallikrein-related peptidase 12 acting via a platelet-derived growth factor B-dependent paracrine pathway. FASEB J 28: 740-751, 2014
28. Wang GL and Semenza GL: Desferrioxamine induces erythropoietin gene expression and hypoxia-inducible factor 1 DNA-binding activity: Implications for models of hypoxia signal transduction. Blood 82: 3610-3615, 1993.

29. Yuan Y, Hilliard G, Ferguson T and Millhorn DE: Cobalt inhibits the interaction between hypoxia-inducible factor-alpha and von Hippel-Lindau protein by direct binding to hypoxia-inducible factor-alpha. J Biol Chem 278: 15911-15916, 2003.

30. Taheem DK, Foyt DA, Loaiza S, Ferreira SA, Ilic D, Auner HW, Grigoriadis AE, Jell G and Gentleman E: Differential Regulation of Human Bone Marrow Mesenchymal Stromal Cell Chondrogenesis by Hypoxia Inducible Factor-1 $\alpha$ Hydroxylase Inhibitors. Stem Cells 36: 1380-1392, 2018.

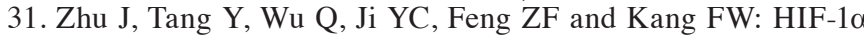
facilitates osteocyte-mediated osteoclastogenesis by activating JAK2/STAT3 pathway in vitro. J Cell Physiol 234: 21182-21192, 2019.

32. Ahani-Nahayati M, Solali S, Shams Asenjan K, Movassaghpour Akbari AA, Talebi M, Zadi Heydarabad M, Baharaghdam S and Farshdousti Hagh M: Promoter methylation status of survival-related genes in MOLT-4 cells co-cultured with bone marrow mesenchymal stem cells under hypoxic conditions. Cell J 20: 188-194, 2018

33. Lolmède K, Durand de Saint Front V, Galitzky J, Lafontan M and Bouloumié A: Effects of hypoxia on the expression of proangiogenic factors in differentiated 3T3-F442A adipocytes. Int J Obes Relat Metab Disord 27: 1187-1195, 2003.

34. Liu G, Chen L, Cai Q, Wu H, Chen Z, Zhang X and Lu P. Streptozotocin induced diabetic mice exhibit reduced experimental choroidal neovascularization but not corneal neovascularization. Mol Med Rep 18: 4388-4398, 2018.

35. Le YZ, Ash JD, Al-Ubaidi MR, Chen Y, Ma JX and Anderson RE: Targeted expression of Cre recombinase to cone photoreceptors in transgenic mice. Mol Vis 10: 1011-1018, 2004.

36. Livak KJ and Schmittgen TD: Analysis of relative gene expression data using real-time quantitative PCR and the 2(-Delta Delta $\mathrm{C}(\mathrm{T}))$ method. Methods 25: 402-408, 2001.

37. Arnaoutova I and Kleinman HK: In vitro angiogenesis: Endothelial cell tube formation on gelled basement membrane extract. Nat Protoc 5: 628-635, 2010.

38. Bock F, Maruyama K, Regenfuss B, Hos D, Steven P, Heindl LM and Cursiefen $C$ : Novel anti(lymph)angiogenic treatment strategies for corneal and ocular surface diseases. Prog Retin Eye Res 34: 89-124, 2013.

39. Sunderkötter C, Goebeler M, Schulze-Osthoff K, Bhardwaj R and Sorg C: Macrophage-derived angiogenesis factors. Pharmacol Ther 51: 195-216, 1991.

40. Nielsen SR and Schmid MC: Macrophages as Key Drivers of cancer progression and metastasis. Mediators Inflamm 2017: $9624760,2017$.

41. Chung AS and Ferrara N: Developmental and pathological angiogenesis. Annu Rev Cell Dev Biol 27: 563-584, 2011.

42. Carmeliet P: Angiogenesis in health and disease. Nat Med 9: 653-660, 2003.

43. Carmeliet P: Angiogenesis in life, disease and medicine. Nature 438: 932-936, 2005

44. Rodriguez A, Friman T, Kowanetz M, van Wieringen T, Gustafsson R and Sundberg C: Phenotypical differences in connective tissue cells emerging from microvascular pericytes in response to overexpression of PDGF-B and TGF- $\beta 1$ in normal skin in vivo. Am J Pathol 182: 2132-2146, 2013.

45. Capitão M and Soares R: Angiogenesis and inflammation crosstalk in diabetic retinopathy. J Cell Biochem 117: 2443-2453, 2016.

46. Sufen G, Xianghong Y, Yongxia $\mathrm{C}$ and Qian P: bFGF and PDGF-BB have a synergistic effect on the proliferation migration and VEGF release of endothelial progenitor cells. Cell Biol Int 35: 545-551, 2011.

47. Kovacevic D, Gulotta LV, Ying L, Ehteshami JR, Deng XH and Rodeo SA: rhPDGF-BB promotes early healing in a rat rotator cuff repair model. Clin Orthop Relat Res 473: 1644-1654, 2015.

48. Bonnet CS and Walsh DA: Osteoarthritis, angiogenesis and inflammation. Rheumatology (Oxford) 44: 7-16, 2005.

49. Park ES, Lee KP, Jung SH, Lee DY, Won KJ, Yun YP and Kim B: Compound $\mathrm{K}$, an intestinal metabolite of ginsenosides, inhibits PDGF-BB-induced VSMC proliferation and migration through G1 arrest and attenuates neointimal hyperplasia after arterial injury. Atherosclerosis 228: 53-60, 2013.

50. Maloney SC, Antecka E, Granner T, Fernandes B, Lim LA, Orellana ME and Burnier MN Jr: Expression of SIRT1 in choroidal neovascular membranes. Retina 33: 862-866, 2013. 
51. Friedlaender GE, Lin S, Solchaga LA, Snel LB and Lynch SE: The role of recombinant human platelet-derived growth factor-BB (rhPDGF-BB) in orthopaedic bone repair and regeneration. Curr Pharm Des 19: 3384-3390, 2013.

52. Wyler von Ballmoos M, Yang Z, Völzmann J, Baumgartner I, Kalka C and Di Santo S: Endothelial progenitor cells induce a phenotype shift in differentiated endothelial cells towards PDGF/ PDGFR $\beta$ axis-mediated angiogenesis. PLoS One 5: e14107, 2010.

53. Miyazaki H, Yoshimatsu Y, Akatsu Y, Mishima K, Fukayama M Watabe T and Miyazono K: Expression of platelet-derived growth factor receptor $\beta$ is maintained by Prox 1 in lymphatic endothelial cells and is required for tumor lymphangiogenesis. Cancer Sci 105: 1116-1123, 2014.

54. Riabov V, Gudima A, Wang N, Mickley A, Orekhov A and Kzhyshkowska J: Role of tumor associated macrophages in tumor angiogenesis and lymphangiogenesis. Front Physiol 5: 75, 2014.
55. Battegay EJ, Rupp J, Iruela-Arispe L, Sage EH and Pech M: PDGF-BB modulates endothelial proliferation and angiogenesis in vitro via PDGF beta-receptors. J Cell Biol 125: 917-928, 1994.

56. Chaoran Z, Zhirong L and Gezhi X: Combination of vascular endothelial growth factor receptor/platelet-derived growth factor receptor inhibition markedly improves the antiangiogenic efficacy for advanced stage mouse corneal neovascularization. Graefes Arch Clin Exp Ophthalmol 249: 1493-1501, 2011.

57. Shah P, Keppler L and Rutkowski J: A review of platelet derived growth factor playing pivotal role in bone regeneration. J Oral Implantol 40: 330-340, 2014.

c) (i)(3) This work is licensed under a Creative Commons C Attribution-NonCommercial-NoDerivatives 4.0 International (CC BY-NC-ND 4.0) License. 